\title{
Knowledge of Eye Care Workers among Students of a School of Optical Dispensing Technology in Birnin Kebbi, Nigeria
}

Monsudi Kehinde Fasasi, ${ }^{1}$ Abayomi Olusola Ayodapo, ${ }^{2}$ Kehinde K Oladigbolu, ${ }^{3}$ Ike Ogbu ${ }^{1}$

${ }^{1}$ Department of Ophthalmology, Federal Medical Centre, Birnin Kebbi, Kebbi State, Nigeria, ${ }^{2}$ Department of Family Medicine, Federal Medical Centre, Birnin Kebbi, Kebbi State, Nigeria, ${ }^{3}$ Department of Ophthalmology, Ahmadu Bello University Teaching Hospital, Shika-Zaria, Nigeria.

\begin{abstract}
Background: Eye care workers comprise of both clinical and non-clinical staff. For effective prevention of blindness and visual impairment the eye care health professionals must work in harmony. Also, the consumer of the eye care servicers must have good knowledge of these categories of workers to prevent financial loss, ocular morbidity from quackery and late hospital presentation. The objective of this study is to assess student's knowledge on the work of eye care professionals at school of optical dispensing technology Birnin Kebbi, Nigeria. Methods: A cross-sectional study was conducted one month among students of School of Optical Dispensing Technology, Birnin Kebbi. A semi-structured questionnaire was used to elicit information which include socio-demographic characteristics, the knowledge of students about eye care team, the composition of eye care team, and the functions of eye care team members. Data entry and analysis was done using SPSS version 20. Results: Seventy one students participated, of which 44(62\%) were males. The mean age of the participants was $23.6 \pm 4.8$ years, with age range between 18-48years. Majority 32 (45.1\%) were in the age group of 23 - 27years. Most 28 (39.4) of the students were in year 2. More than two-third $(97.2 \%)$ of the students agreed that eye care was a team work. About $98.2 \%$ of the students were aware that different cadres of eye care workers exist. Sources of information about eye care team among the students was mainly during workshop or hospital seminar 31 (43.7\%) organised by the department of ophthalmology. Conclusion: The awareness and knowledge about different cadres of eye care workers was high among the students. The participants agreed that eye care is a team work. The sources of information about eye care team was hospital seminal/workshop organised by the department of ophthalmology.
\end{abstract}

Keywords: eye care team; eye care workers; Kebbi State; school optical and dispense.

\section{INTRODUCTION}

Eye care workers are health workers that are involved in the provision of eye care services. It comprises of clinical and non-clinical staff. The clinical staff include ophthalmologist, medical officer/ resident doctor, cataract surgeon, optometrist, refractionist, nurses (ophthalmic, anaesthetist and general), optician, orthoptist, eye instrument technician and record officer. While, non-clinical staff include: counsellor, driver, clerk, cleaner and cataract manager. Categories of eye care workers needed for effective prevention of blindness and visual impairment were previously reported in Nigeria by Odusote ${ }^{1}$ and Adepoju et al. ${ }^{2}$ in 1998 and 2011 respectively. This was further elaborated by VISION 2020: Right to Sight. For effective service delivery VISION 2020 recommended specific number of different eye care worker cadre (Table1) to a million population in cataract services ${ }^{3}$. However, the number of eye care workers are less in developing countries compared to developed countries, and this is militating against achieving VISION 2020 target. In-fact the small

\begin{tabular}{|c|c|}
\hline Cadres & $\begin{array}{l}\text { VISION } 2020 \text { target } \\
\text { per million population }\end{array}$ \\
\hline Ophthalmologist & 4 \\
\hline Cataract surgeon & 10 \\
\hline Ophthalmic clinical officers & 10 \\
\hline Ophthalmic nurses & 10 \\
\hline Optometrist & 20 \\
\hline Mid-level refractionist & 20 \\
\hline Cataract surgery rate(CSR) & 2000 \\
\hline $\begin{array}{l}\text { Cataract surgeries per sur- } \\
\text { geon (Surgical efficiency } \\
\text { ratio) }\end{array}$ & 500 \\
\hline
\end{tabular}

number of eye care workers in developing countries are mal-distributed, most are in the towns leaving most rural areas with no personnel to take care of the large population. ${ }^{4,5}$ To achieve better eye care service the service providers (eye care team) and consumer must work hand in hand. Better quality and reasonable charge (VISION 2020 goal) by eye

Correspondence: Dr Monsudi Kehinde Fasasi, Department of Ophthalmology, Federal Medical Centre Birnin Kebbi, PMB 1126, Birnin Kebbi, Kebbi State, Nigeria. Email: kfmoshood@yahoo.co.uk. Phone: +2348027938305. Article received: 2018-04-18. Article accepted: 2019-11-22. 
Monsudi et al. Knowledge of Eye Care Workers among Students of a School of Optical..

team must be met. The good knowledge of different cadres of eye care workers by the consumers help in preventing morbidity from quackery, financial loss and delay in assessing eye care services. ${ }^{6}$ There were many previous studies ${ }^{2,4,7-12}$ on the awareness about eye care workers. However, most of these studies were population and hospital based, while few $^{6}$ were reported among students, who are important in the spread of eye health education through discussion with friends, parents, and relatives. It is then of paramount importance that this study is conducted among these students to know their knowledge about cadre of eye care workers, to identify the gaps and gain insight on eye care services delivery in Kebbi State.

\section{METHODS}

This was a descriptive cross-sectional study conducted in August 2017 among the students of the school of optical dispensing technology Birnin Kebbi, using pre-tested semi-structured questionnaires. The school of optical dispensing technology was the first of its kind to be established in Nigeria on the $2^{\text {nd }}$ of February 2007 by the Federal Medical Centre Birnin Kebbi. It awards Ordinary National Diploma (OND). Starting with 6 students, the school now boasts of 73 students and 10 lecturers.

The questionnaire was administered to all the students in the school to extract information about the socio-demographic characteristics (age, sex, religion, tribe and year of study), knowledge of students about eye care team, the composition of eye care team, the roles of ophthalmologist, optometrist, optician, ophthalmic nurses, ophthalmic medical assistant, and ophthalmic photographer. The questionnaire was pre-tested among the students of Kebbi State School of nursing Birnin Kebbi and the problems noticed during the pre-test were corrected.

The data was collated and analysed using Statistical Package for the Social Science version 20 (SPSS 2006, Chicago, Illinois, USA). Analysis was done using simple frequency. The Fischer exact was used to test association between parameters. The statistical significance was taken as $\mathrm{P}<0.05$

The ethical clearance for the study was obtained from Research and Ethical Committee of the Federal Medical Centre Birnin Kebbi. Informed written consent was also obtained after the study was explained to each participant.

\section{RESULTS}

Seventy-one students participated and returned the questionnaires given a response rate of $97.2 \%$. There were more males $44(62 \%)$ than females 28 $(38 \%)(\mathrm{M}: \mathrm{F}=1.6: 1)$, Table 2 . The mean age of the

\begin{tabular}{|c|c|c|c|}
\hline \multirow{2}{*}{$\begin{array}{c}\text { Age group } \\
\text { (years) }\end{array}$} & \multicolumn{2}{|c|}{ Sex } & \multirow[t]{2}{*}{ Total } \\
\hline & Male & Female & \\
\hline $18-22 y r s$ & 13 & 18 & 31 \\
\hline $23-27 y r s$ & 24 & 8 & 32 \\
\hline $28-32 y r s$ & 4 & 1 & 5 \\
\hline $33 y r s+$ & 3 & 0 & 3 \\
\hline Total & 44 & 27 & 71 \\
\hline
\end{tabular}

\begin{tabular}{|l|c|c|}
\hline \multicolumn{2}{|l|}{$\begin{array}{l}\text { Table 3. Socio-demographic characteristics of the } \\
\text { participants. }\end{array}$} \\
\hline Characteristics & Frequency & $\%$ \\
\hline Religion & 55 & 77.5 \\
Islam & 16 & 22.5 \\
Christian & & \\
Marital status & 18 & 25.4 \\
Married & 51 & 71.8 \\
Single & 2 & 2.8 \\
Divorced & & \\
Tribe & 47 & 66.2 \\
Hausa & 6 & 8.5 \\
Yoruba & 18 & 25.4 \\
Others & & \\
Student level year & 19 & 26.8 \\
Year 1 & 28 & 39.4 \\
Year 2 & 24 & 33.8 \\
Year 3 & \\
\hline
\end{tabular}

participants was $23.6 \pm 4.8$ years, with age range between 18-48years. Majority $32(45.1 \%)$ were in the age group of 23 - 27years followed by 18- 22years $31(43.7 \%)$. Most of the participants were Hausa $47(66.2)$, single 51 (71.8\%) and practise Islam 55(77.5\%).

Majority 28 (39.4) of the participants were in year 2, (Table 3). More than two-third (97.2\%) of the students agreed that eye care was a team work. About $98.2 \%$ of the respondents were aware that different cadres of eye care workers exist. Majority of the participants agreed that the ophthalmologist $95.8 \%$, optometrist $93 \%$, ophthalmic nurses $93 \%$, optician 94.4\%, optician dispenser $90.1 \%$, ophthalmic anaesthetist $78.9 \%$, cataract surgeon $73.2 \%$, cleaner in the eye clinic $71.8 \%$, eye instrument technician $70.4 \%$, refractionist $67.6 \%$ and record officer $60.6 \%$ were part of eye care team. While, half of the participants understood that cataract manager, clerk and driver in the eye clinic were part of the eye care workers (Table 4). However, less than a quarter of the students agreed that general nurses, resident doctor/medical officer, orthoptist and counsellor were part of eye care team (Table 4).

Sources of information about eye care team among the study participants was mainly during workshop or hospital seminar $31(43.7 \%)$ organised by the department of ophthalmology Federal Medical Centre, Birnin Kebbi (Table 5). 
Monsudi et al. Knowledge of Eye Care Workers among Students of a School of Optical..

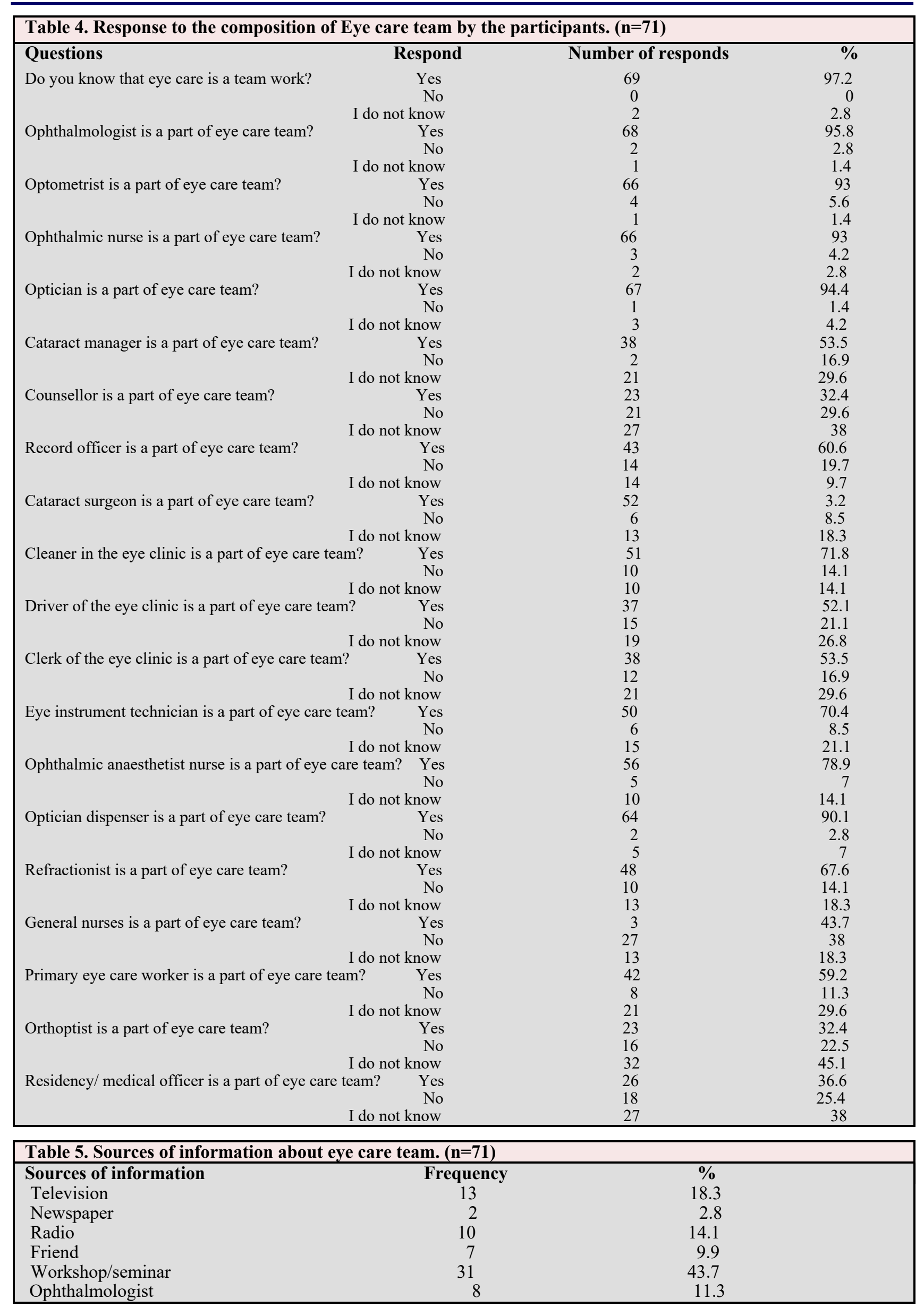




\section{DISCUSSION}

Most of the participants were males with an age

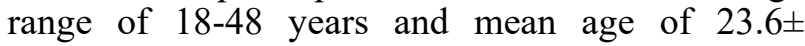
4.8years. The participants' gender characteristics was different from what was reported by Owoeye et al. ${ }^{6}$ despite the similarity in the ages of the participants in the two studies. The difference might be because of smaller number of participants in our study. About $98.2 \%$ of the respondents in our study were aware that different cadres of eye care workers exist and this was more than $35 \%$ reported by Owoeye et al. ${ }^{6}$ The difference may be explained by the study participants being opticians in training, hence have better knowledge about eye care cadres. The students have high knowledge of clinical eye care professionals (ophthalmologist 95.8\%, optometrist $93 \%$ and ophthalmic nurses 93\%) which was far better than previous similar study in Nigeria. ${ }^{6}$ This difference may also be explained by our study groups being part of the eye care team. However, they had poor knowledge about some of the clinical (general nurses, resident doctor/medical officer, orthoptist, and counsellor) and non-clinical eye care staff. This was not surprising because these sets of workers were not commonly employed in Nigeria Hospitals. This was in agreement with previous studies. ${ }^{5,13,14}$ The presence of right proportion of eye care workers has been known to increase the eye care services delivery. ${ }^{2,6}$ While, the good knowledge of different cadres of eye workers by the consumers help in the prevention of morbidity from quackery, it will also reduce financial loss and delay in assessing quality eye care services. ${ }^{6}$ The good knowledge of eye care cadre in our study may be a positive sign that the eye care services delivery in Kebbi state is on the upward trend. Hospital seminar/workshop organised by ophthalmology department were the main sources of information of the respondents about knowledge on the eye care workers. This was different from most previous studies. ${ }^{15-17}$ but similar to what was reported by Monsudi et al. ${ }^{18}$ The difference may be because the students took the workshop/ seminar as part of learning and school program. Also worthy of note is the fact that most of their teachers are from ophthalmology department. Our study revealed the importance of hospital seminar and workshop as a tool in the dissemination of health education. In our study mass media account for $35.2 \%$ as a source of information and this was less than what was reported by Adegbehingbe and Bisiriyu. ${ }^{16}$ Newspaper was ranked lowest among the participants as a sources of information, this was similar to what was reported from Ile Ife Osun state, Nigeria ${ }^{16}$ and by Ichhpujani et al in North India. ${ }^{17}$ This shows that most of the students do not read newspaper, possibly because they cannot afford it or see the need for it.

\section{CONCLUSIONS}

The awareness and knowledge about different cadres of eye care workers among the students was high. Furthermore the participants agreed that eye care is a team work. The sources of information about eye care was hospital seminar/workshop organized by the department of ophthalmology. Hospital management should continue to support hospital seminar/workshop because of it important in disseminations of eye care information among the students.

\section{Limitations of the study}

Small numbers of study population.

\section{Conflict of interest and financial disclosure: None}

eastern Nigeria. Human Resources for Health2009;7:38. https://doi.org/10.1186/14784491-7-38.

1. Odusote KA. Human resources development for the prevention of blindness in Anglophone West Africa. West Afr J Med. 1998;17(1):1-8.

2. Adepoju FG, Ayanniyi AA, Pam V, Akanbi TB. Human resource development for Vision 2020 in developing countries: a change from absolute numbers. Eur J Ophthalmol. 2011;21 (6):820-825.

3. Palmer JJ, Chinanayi F, Gilbert A, Pillay D, Fox S, Jaggernath J, et al. Trends and implications for achieving VISION 2020 human resources for eye health targets in 16 countries of sub-Saharan Africa by the year 2020. Human resources for health. 2014;12:45

4. Fasasi K M, Ayanniyi AA. Evaluating resource for cataract surgical services in Kebbi, Nigeria. Taiwan J Ophthalmol 2018; 8:87-92

5. Boniface Ikenna Eze, Ferdinnd Chinedu Maduka-Okafor.An assessment of the eye care workforce in Enugu State, south-
6. JFA Owoeye, DS Ademola-Popoola, BJ Adekoya, BD Balogun, VA Olatunji. A study of the level of awareness, of different cadre of eye care providers, Among tertiary Institution Students in Nigeria. Ann Biomed Sci 2013; 12 (1) 76:83

7. Eze BI, Okoye O, Aguwa EN. Public's knowledge of the differences between ophthalmologists and optometrists: a critical issue in eye care service utilisation. Int $\mathrm{J}$ Ophthalmol. 2016;9(9):1336-1342.

8. Wilson MR, Lee DA, Bourque L. Does the public understand the differences between ophthalmologists and optometrists? Ophthalmic Epidemiol 1994;1(3):121-129.

9. Guffey R, Juzych N, Juzych M. Patient knowledge of physician responsibilities and their preferences for care in ophthalmology 
teaching clinics. Ophthalmology 2009;116 (9):1610-1614.

10. Zeller M, Perruzza E, Austin L, Vohra S, Stephens D, Abdolell M, McKneally M, Levin AV. Parental understanding of the role of trainees in the ophthalmic care of their children. Ophthamology. 2006;113 (12):2292-2297

11. Ayanniyi AA, Olatunji FO, Adeboye A, Ayanniyi RO. Awareness and knowledge of eye care providers among government workers in Ilorin, Nigeria Niger Post grad. Med J. 2010;17 (2):133-137.

12. Soroka M. Knowledge and use of eye care services by college and professional students: implications for the profession. Am J Opt Physiol Opt. 1979;56(3):187-192.

13. World Health Organization: The World Health Report 2000. Health Systems: Improving Performance. Geneva. 2000

14. Nwosu SNN: Resources for eye health services in Anambra State I: Ophthalmic manpower. Nigerian Medical Journal. 1994, 27 (2\&3): 5054.

Citation: Monsudi KF, Ayodapo AO, Oladigbolu KK, Ogbu I. Knowledge of Eye Care Workers among Students of a School of Optical Dispensing Technology in Birnin Kebbi, Nigeria. JCMS Nepal. 2019; 15(4):291-5.
15. Noopur Gupta, Praveen Vashist, Radhika Tandon, Sanjeev K. Gupta, Mani Kalaivani, S. N. Dwivedi. Use of traditional eye medicine and self-medication in rural India: A populationbased study.2017 PLoS ONE 12(8): e0183461. https://doi.org/10.1371/journal.pone.0183461

16. Adegbehingbe BO, Bisiriyu LA. (2008) Knowledge, attitudes, and self care practices associated with glaucoma among hospital workers in Ile-Ife, Osun State, Nigeria. Tanzan J Health Res 10:240-245. pmid:19402586

17. Ichhpujani P, Bhartiya S, Kataria M, Topiwala $P$. Knowledge attitude and selfcare practice associated with glaucoma among hospital personnel in a tertiary care center in North India. J Curr Glaucoma Prac 2012; 6: 108-112.

18. KF Monsudi, ES Saka, AO Ayodapo. Health workers awareness and knowledge of glaucoma in tertiary hospital in Birnin Kebbi, Nigeria. Nigeria. Ophthalmology Research :An International Journal.2018; 8(2): 1-8 